\title{
ANÁLISE DA ARBORIZAÇÃO DE VIAS PÚBLICAS DO BAIRRO DE RAMOS - VIÇOSA/MG
}

\author{
Clarissa Gusmão Figueiró ${ }^{1}$, Lucas de Freitas Fialho², Carlos Miguel Simões da \\ Silva ${ }^{2}$, Welliton Lelis Cândido ${ }^{2}$, Wagner Davel Canal ${ }^{2}$ \\ ${ }^{1}$ Mestrando em Ciência Florestal, Universidade Federal de Viçosa, Viçosa-MG, \\ Brasil (clarissagfigueiro@gmail.com) \\ ${ }^{2}$ Mestrando em Ciência Florestal, Universidade Federal de Viçosa, Viçosa-MG, \\ Brasil \\ ${ }^{3}$ Doutorando em Ciência Florestal, Universidade Federal de Viçosa, Viçosa-MG, \\ Brasil
}

Recebido em: 03/10/2016 - Aprovado em: 21/11/2016 - Publicado em: 05/12/2016 DOI: 10.18677/EnciBio_2016B 002

\begin{abstract}
Objetivou-se analisar a arborização viária do bairro de Ramos, da cidade de ViçosaMG. Foram levantados 121 indivíduos, pertencentes a 18 espécies diferentes. O total de família encontrada foi 13 , com apenas um indivíduo morto. Da totalidade de espécies amostradas, $65 \%$ foram de espécies exóticas. O local de estudo apresentou $6,5 \mathrm{~km}$ de calçadas, com um índice de plena ocupação de 167 arvores $/ \mathrm{Km}$. O bairro em estudo encontra-se pouco arborizado, apenas $11 \%$ de ocupação apresentando um déficit de aproximadamente 148 arvores $/ \mathrm{Km}$. Quando analisado as condições de altura total dos indivíduos, as classes $(<5 \mathrm{~m})$ e $(5<\mathrm{h}>$ $10 \mathrm{~m}$ ) tiveram destaque. A maior parte dos indivíduos arbóreos encontra-se em passeios de 1,5 a $3 \mathrm{~m}$ de comprimento. Os indivíduos arbóreos que não se aproximaram da fiação destacaram-se sobre os demais indivíduos levantados (67\%). Dentre os indivíduos levantados, $42 \%$ enquadram na fase velha e adulta. Quanto a classe de diâmetro de copa, $47 \%$ se enquadraram na classe $<4 \mathrm{~m}$ e $35 \%$ na classe de 4 a $7 \mathrm{~m}$. Assim, conclui-se que o Bairro de Ramos possui uma insatisfatória intensidade de arborização e uma inadequada diversidade de espécies.
\end{abstract}

RESUMO

PALAVRAS-CHAVE: Diagnostico; florestas urbanas; planejamento.

\section{ANALYSIS OF AFFORESTATION PUBLIC ROADS OF RAMOS DISTRICT - VIÇOSA / MG}

\begin{abstract}
This study aimed to analyze the road afforestation Ramos district in the city of Viçosa-MG. 121 individuals, belonging to 18 different species were raised. Total family found were 13 , with only a dead tree. Of all the species sampled, $65 \%$ were exotic. The study site had $6.5 \mathrm{~km}$ of sidewalks, with an index of full occupancy of 167 trees $/ \mathrm{km}$. The district study is little woody, only $11 \%$ occupancy showing a deficit of about 148 trees $/ \mathrm{km}$. When analyzed the conditions of full height of the trees, the class $(<5 \mathrm{~m})$ and $(5<\mathrm{h}>10 \mathrm{~m})$ were highlighted. The majority of trees are in sight from 1.5 to $3 \mathrm{~m}$ in length. The arboreal individuals who did not approach the wiring
\end{abstract}


stood out over the others raised subjects (67\%). Among the individuals surveyed, $42 \%$ fall into the old and adulthood. As for crown diameter class, $47 \%$ fit in the class $<4 \mathrm{~m}$ and $35 \%$ in class 4 to $7 \mathrm{~m}$. Thus, it is concluded that the Ramos district has an unsatisfactory intensity of afforestation and inadequate diversity of species.

KYEWORDS: diagnosis; urban forests; planning

\section{INTRODUÇÃO}

O processo de urbanização promove transformações no ambiente natural das cidades, o que afeta diretamente a sua paisagem e promove, na maioria das vezes, degradações dos fragmentos remanescentes de vegetação nativa (MELO et al., 2011). A implantação e manutenção de projetos de arborização é uma técnica que pode contornar parcialmente essa situação, reduzindo a artificialidade das cidades ao inserir componentes naturais ao local (BOBROWSKI et al., 2012). Todavia, a arborização de um espaço urbano não pode ser implantada sem um planejamento detalhado considerando critérios técnicos, ambientais e orçamentários, a fim de evitar transtornos futuros.

A avaliação dos indivíduos arbóreos é etapa fundamental durante todo o processo de arborização de uma cidade, desde a implantação até o acompanhamento contínuo que deve haver nos anos seguintes. Essa avaliação é necessária para o desenvolvimento de práticas de manejo, de diagnóstico para o replanejamento e de apoio para o planejamento de novas áreas verdes nos meios urbanos (SALVI et al., 2011). De acordo com SANTOS et al. (2015), as avaliações proporcionam a prevenção de transtornos futuros e propõe intervenções adequadas às características do local avaliado, por meio da constatação de problemas como incidência de pragas, doenças e avarias provocados por atos de vandalismo. MARTINI \& BIONDI (2015) ressaltam a importância dessa etapa de coleta de informações básicas de quantificação, qualificação e espacialização da vegetação urbana.

De acordo com KRAMER \& KRUPEK (2012) e MALTA et al. (2012), deveriam ser preocupação dos municípios conhecer sobre a flora urbana. Tais informações permitem desenvolver e aprimorar projetos de arborização urbana que reconheçam elementos paisagísticos e naturais da região. Segundo BUCKERIDGE (2015) e MARTINI \& BIONDI (2015), para que a vegetação urbana possa exercer suas funções ecológica, estética e social é necessário que haja uma distribuição adequada dos elementos arbóreos em uma convivência equilibrada com os demais componentes urbanos. Além disso, é ideal que haja uma conexão entre os próprios elementos arbóreos, permitindo que as interações entre eles sejam o mais próximo do natural.

Nesse contexto, objetivou-se avaliar a arborização urbana de um bairro do município de Viçosa, no estado de Minas Gerais, e a partir dela fornecer subsídios para planejamento e aplicação de medidas mitigadoras no local estudado.

\section{MATERIAL E MÉTODOS}

\section{Caracterização da área de estudo}

O presente estudo foi realizado no município de Viçosa $\left(20 \% 5^{\prime} 14^{\prime \prime}\right.$ de latitude Sul e 4252'54 de longitude Oeste, altitude de 646 m), localizada na região da Zona da Mata do estado de Minas Gerais, entre as coordenadas geográficas. Possui uma população de quase 80 mil habitantes e uma área de 299,418 km² (IBGE, 2010). O 
bairro da cidade escolhido para realização do estudo foi o bairro de Ramos. Este bairro caracteriza-se em sua maioria como residencial, relativamente jovem e de classe média alta. Este bairro está localizado na região central da cidade e tem 1.497 habitantes (IBGE, 2010).

Foram utilizados mapas temáticos (Figuras 1,2,3 e 4) para caracterização e conhecimento da área em estudo. A carta geográfica da cidade de Viçosa, contendo malha viária, malha hidrográfica, e curvas de nível, foi adquirida junto ao website oficial do IBGE (Instituto Brasileiro de Geografia e Estatística) em escala 1:50000. Foi utilizado o software ArcGis 10.1 para análise espacial das variáveis geográficas e plotagem dos resultados em mapas temáticos.

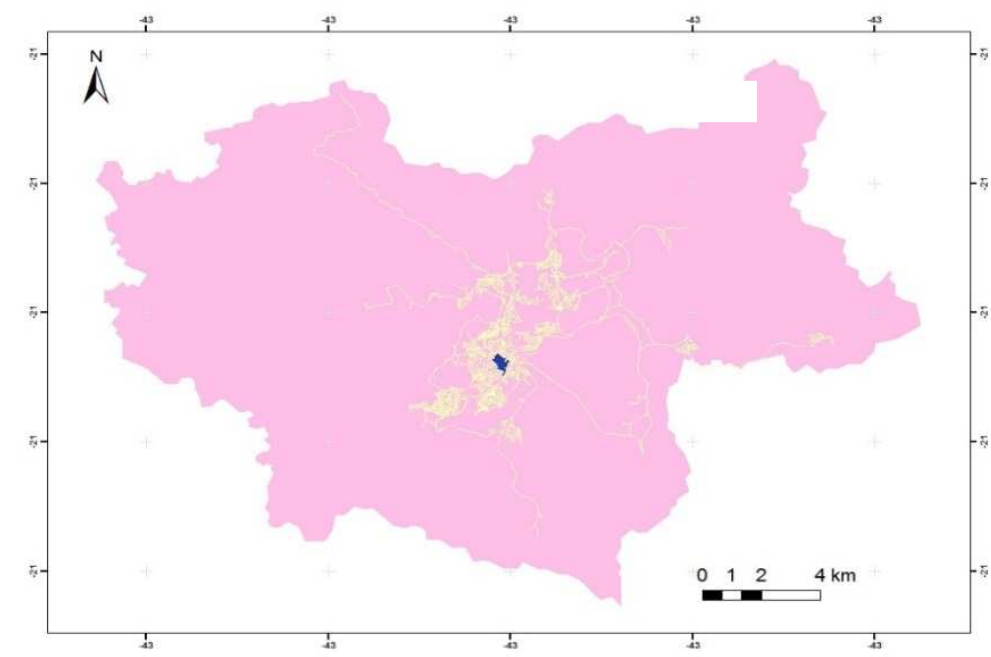

FIGURA 1. Carta geográfica da cidade de Viçosa.

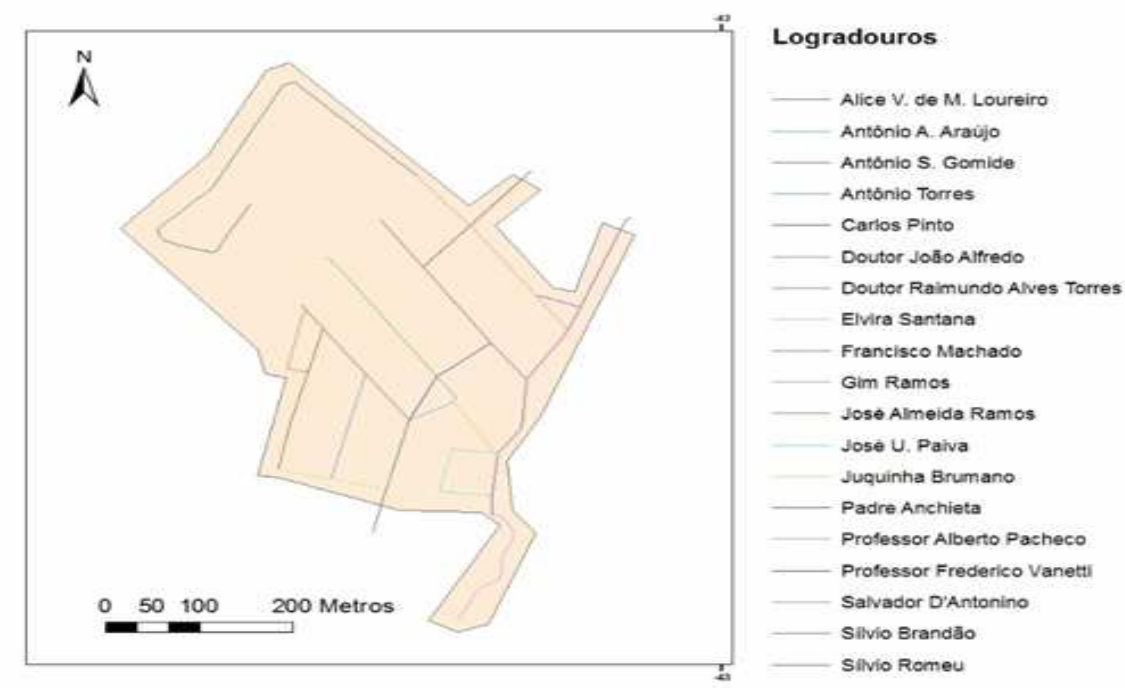

FIGURA 2. Malha viária do bairro de Ramos. 


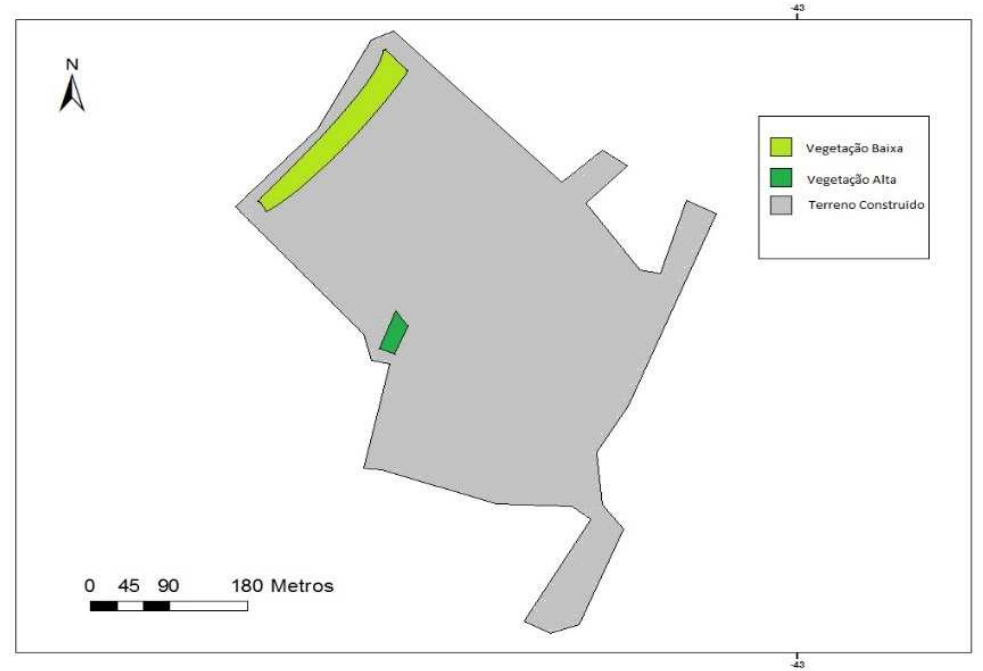

FIGURA 3. Mapa com zoneamento aproximado por tipo de vegetação.

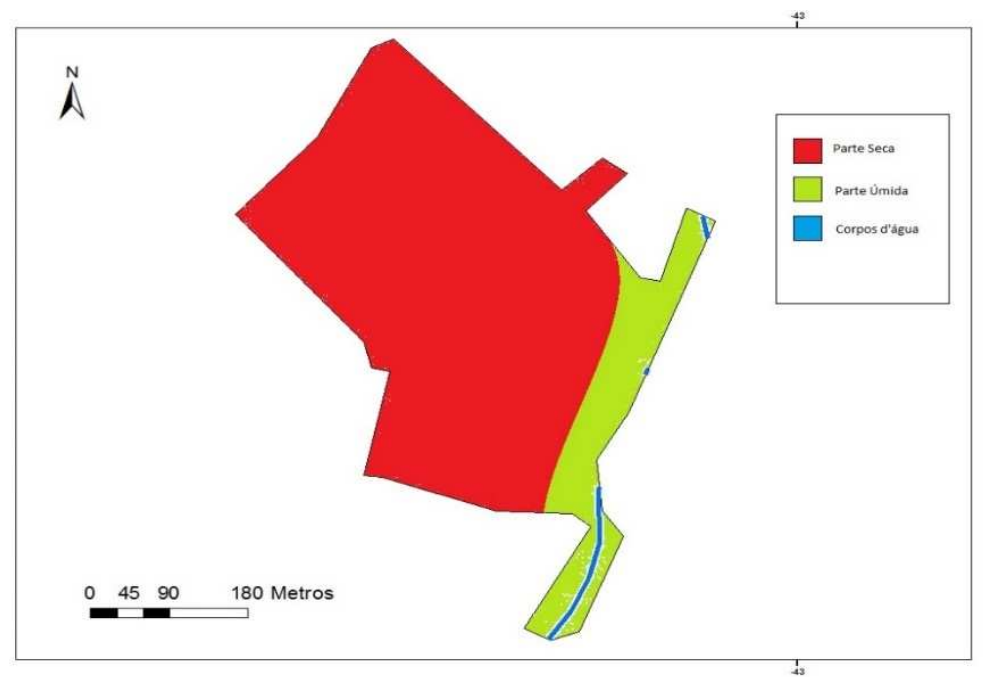

FIGURA 4. Mapa com zoneamento aproximado por hidrografia.

\section{Coleta e análise dos dados}

O método de inventário utilizado foi o Censo (100\%), no qual é adequado para áreas com pequeno número de indivíduos, uma vez que pode-se obter dados mais próximos da realidade, com o mínimo de erros. Assim, para a classificação do desenvolvimento das espécies, os indivíduos foram codificados como I (muda), II (jovem), III (adulta) e IV (velha). Diante destas informações, pode-se avaliar a homogeneidade da arborização do bairro.

De acordo com as condições externas das raízes, os indivíduos foram classificados em quatro categorias, foram elas: I (nenhum - raiz não se encontra exposta); II (aponta - raiz está apontando na superfície do solo); III (quebra - a raiz se expõe na superfície); IV (destrói - ao emergir na superfície quebra a estrutura superficial).

Já para a interação com as fiações do sistema de distribuição de energia elétrica, os indivíduos foram classificados em: I (não aproxima); II (abaixo - a fiação está abaixo da copa da espécie); III (meio - a fiação encontra-se no meio da copa da espécie); IV (acima - a fiação encontra-se acima da copa da espécie). 
Também foi avaliado o tamanho da copa, e assim foram codificados em: I (espécies de diâmetro de copa menor que $4 \mathrm{~m}$ ); II (espécies de diâmetro de copa entre 4 e $7 \mathrm{~m}$ ); III (espécies de diâmetro de copa entre 7 e $10 \mathrm{~m}$ ); IV (espécies de diâmetro de copa maior que $10 \mathrm{~m}$ ). De acordo com a altura, os indivíduos foram codificados em: 0 - espécies com altura menor que $5 \mathrm{~m} ; 1$ - espécies com altura entre 5 e 10 m; 2 - espécies com altura entre 10 e 15 m; 3 - espécies de diâmetro de copa maior que $15 \mathrm{~m}$. Os dados foram avaliados por meio de estatística descritiva.

\section{RESULTADOS E DISCUSSÃO}

$\mathrm{Na}$ Tabela 1 é apresentado o levantamento da quantidade de indivíduos arbóreos encontrados no bairro avaliado. Foram registrados 121 indivíduos, pertencentes a 18 espécies diferentes. O total de famílias encontradas foram 13, com apenas um indivíduo morto. Da totalidade de espécies amostradas, seis são classificadas como espécies nativas, 11 são exóticas. As famílias botânicas com maior número de espécies nas cidades avaliadas foram: Bignoniaceae (2), Fabaceae mimosoideae (2), Fabaceae caesalpinioideae (2) e Myrtaceae (2).

Quando analisado o número de indivíduos, percebe-se que 65\% são de espécies exóticas. Esse dado está de acordo com a afirmação de LORENZI (2002), que relata que a maioria das plantas arbóreas cultivadas em ruas, avenidas, praças e jardins do Brasil são exóticas. MARTINI \& BIONDI (2015) evidenciam a relevância do uso de espécies nativas da região, como forma de trazer benefícios aos espaços urbanos. Desta maneira, a utilização de espécies nativas propiciaria uma arborização harmoniosa e com as concepções da conservação biológica. A alta aplicação de espécies exóticas no Brasil pode ser justificada pela ausência de informações sobre a flora brasileira e seu potencial paisagístico, além as espécies ameaçadas de extinção.

O bairro avaliado apresenta $6,5 \mathrm{~km}$ de calçadas, que representa um índice de plena ocupação de 167 arvores/Km. Este índice está relacionado ao número de árvores por quilômetro de rua ou de calçada. A aplicação deste índice indica a escassez ou abundância de árvores na rua. $\mathrm{O}$ bairro em estudo encontra-se pouco arborizado, apenas $11 \%$ de ocupação apresentando um déficit de aproximadamente 148 arvores $/ \mathrm{Km}$. Esse déficit de ocupação pode causar no bairro problemas relacionados ao aumento da temperatura dos passeios em dias ensolarados, o que pode causar desconforto para as pessoas que transitam neste local. Uma vez que, a redução da incidência direta de luz solar e o aumento da umidade relativa do ar, proporcionados pela arborização urbana, podem reduzir até $4^{\circ} \mathrm{C}$ a temperatura ambiente (MILANO \& DALCIN, 2000).

De acordo com alguns autores, dentre eles MILANO \& DALCIN (2000), cada espécie participante de um inventário florístico urbano não deve ultrapassar $15 \%$ do total de indivíduos arbóreos. Valores maiores que esta percentagem pode representar riscos de pragas e doenças, o que pode prejudicar a sobrevivência das espécies. Deste modo, as espécies Alfeneiro e Murta, com frequência absoluta em ambas de $24 \%$, não atenderam a esta recomendação. 
TABELA 1 - Distribuição quantitativa das espécies encontradas na arborização viária do bairro de Ramos, com os seus respectivos nomes comuns e científicos, família, frequência absoluta dos indivíduos amostrados (Fr. Absol.) e frequência relativa em \% (Fr. Relat.)

\begin{tabular}{ccccc}
\hline $\begin{array}{c}\text { Nome } \\
\text { Comum }\end{array}$ & Nome Científico & Família & $\begin{array}{c}\text { Fr. } \\
\text { Absol. }\end{array}$ & $\begin{array}{c}\text { Fr. } \\
\text { Relat }\end{array}$ \\
\hline Alfeneiro & Ligustrum lucidum & Oleaceae & 24 & $20 \%$ \\
\hline Murta & Murraya paniculata & Myrtaceae & 24 & $20 \%$ \\
\hline Oiti & Licania tomentosa & Chrysobalanaceae & 14 & $12 \%$ \\
\hline Quaresmeira & Tibouchina granulosa & Melastomataceae & 13 & $11 \%$ \\
\hline Sibipiruna & Caesalpinia pluviosa & $\begin{array}{c}\text { Fabaceae } \\
\text { caesalpinioideae }\end{array}$ & 10 & $8 \%$ \\
\hline Palmeira & Não identificado & Arecaceae & 8 & $7 \%$ \\
\hline Jacarandá & Jacaranda mimosifolia & Bignoniaceae & 6 & $5 \%$ \\
\hline Mata-de-vaca & Bauhinia forficata & Clethraceae & 6 & $5 \%$ \\
\hline Espirradeira & Neriumo leander & Apocynaceae & 4 & $3 \%$ \\
\hline Pinus & Pinus Taeda & Pinaceae & 3 & $2 \%$ \\
\hline Ipê-amarelo & Handroanthus serratifolius & Bignoniaceae & 2 & $2 \%$ \\
\hline $\begin{array}{c}\text { Angico } \\
\text { Vermelho }\end{array}$ & Andadenanthera macrocarpa & $\begin{array}{c}\text { Fabaceae } \\
\text { mimosoideae }\end{array}$ & 1 & $1 \%$ \\
\hline Hibisco & Hibiscus L. & Malvaceae & 1 & $1 \%$ \\
\hline Jacaré & Piptadenia gonoacantha & $\begin{array}{c}\text { Fabaceae } \\
\text { mimosoideae }\end{array}$ & 1 & $1 \%$ \\
\hline Magnólia & Magnolia L. & Magnoliaceae & 1 & $1 \%$ \\
\hline Pau-brasil & Caesalpinia echinata & $\begin{array}{c}\text { Fabaceae } \\
\text { caesalpinioideae }\end{array}$ & 1 & $1 \%$ \\
\hline Pitanga & Eugenia uniflora & Myrtaceae & 1 & $1 \%$ \\
\hline Morta & --- & --- & 1 & $1 \%$ \\
\hline & & Total & 121 & $100 \%$ \\
\cline { 2 - 5 } & & & &
\end{tabular}

$\mathrm{Na}$ Figura 5 são apresentadas as condições de altura dos indivíduos encontrados no Bairro de Ramos. A classe de altura total $(<5 \mathrm{~m})$ teve destaque quanto ao número de indivíduos amostrados (46\%). Porém, observa-se que valores próximos foram obtidos para a classe $(5<\mathrm{h}>10 \mathrm{~m})$. Neste bairro, o número de indivíduos concentra-se nas menores classes e vai decaindo nas classes de maior altura, o que pode qualificar uma distribuição hipsométrica tipo "jota invertido". De acordo com GONÇALVES \& PAIVA, (2004), recomenda-se não realizar a implantação de espécies arbóreas com altura total inferior a 2,50 m. De acordo com este estudo, as mudas têm mais chance de sobreviver se tiverem com alturas maiores, portanto próximo da fase adulta, quando forem submetidas ao plantio. 


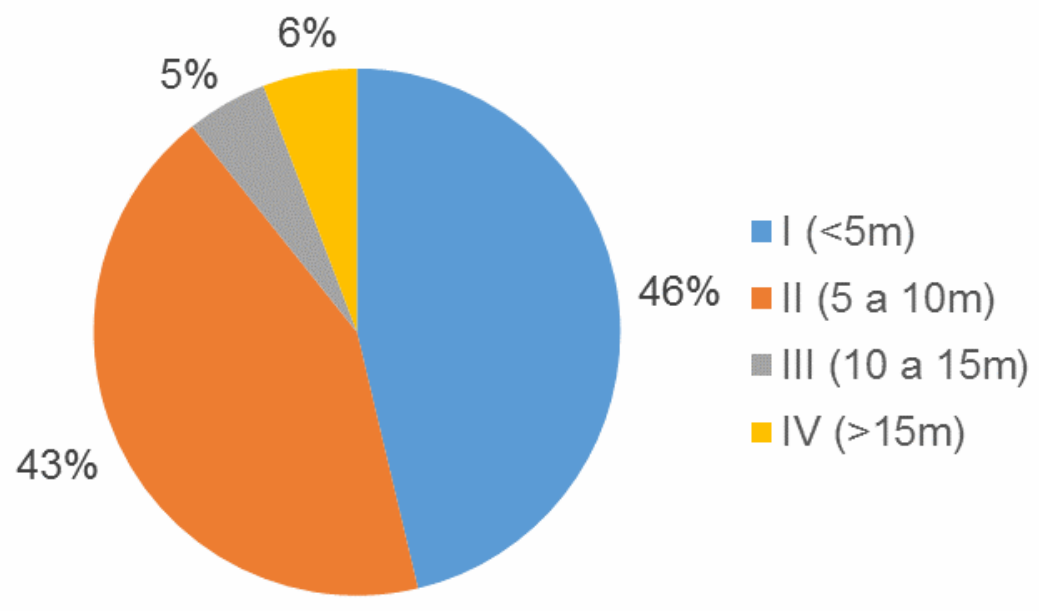

FIGURA 5. Classe de altura dos indivíduos.

Na Figura 6 são apresentadas as condições do passeio onde os indivíduos são encontrados. A maior parte dos indivíduos arbóreos se encontra em passeios de 1,5 a $3 \mathrm{~m}$ de comprimento. Observou-se que os indivíduos levantados estavam localizados próximos aos muros das residências. Recomenda-se uma distância média de $1 \mathrm{~m}$ de distância do meio fio, o que foi atendido neste estudo. Quando espécies arbóreas são plantadas nas proximidades de muros pode haver danos como levantamento e rachadura da estrutura da resistência promovida pelas raízes (SILVA FILHO et al., 2002).

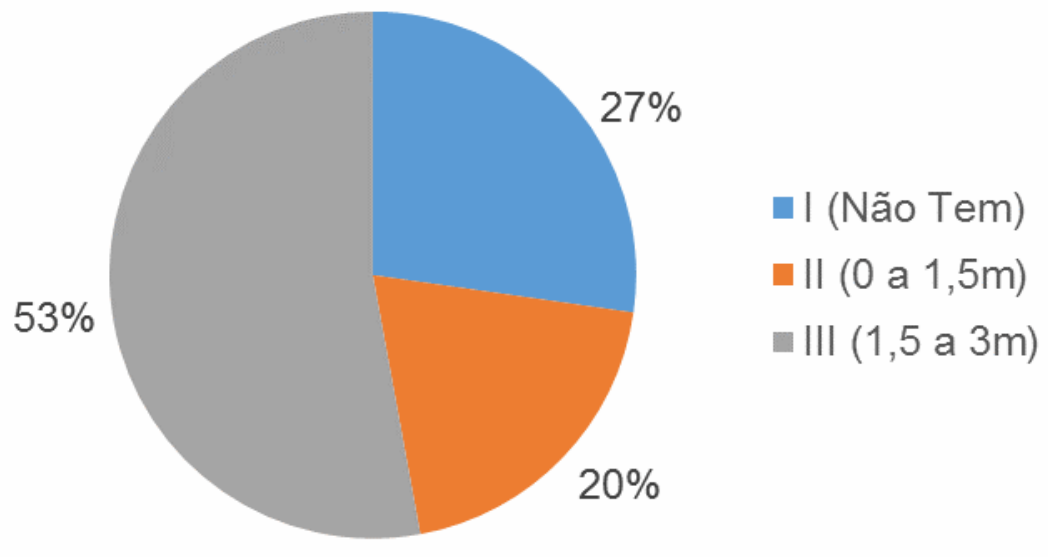

FIGURA 6. Comprimento dos passeios encontrados no Bairro de Ramos.

Na Figura 7 é apresentada a condição da fiação onde os indivíduos são encontrados no Bairro de Ramos. Os indivíduos arbóreos que não se aproximaram da fiação destacaram-se sobre os demais indivíduos levantados (67\%). $17 \%$ dos indivíduos se encontraram no meio da fiação e $3 \%$ acima da fiação. Esta característica também foi encontrada por ALMEIDA \& RONDO, (2010). Esses autores atribuem a ausência de diretrizes eficazes para a arborização urbana pois, a rede de distribuição de energia causa dos conflitos entre as árvores e os elementos urbanos. 


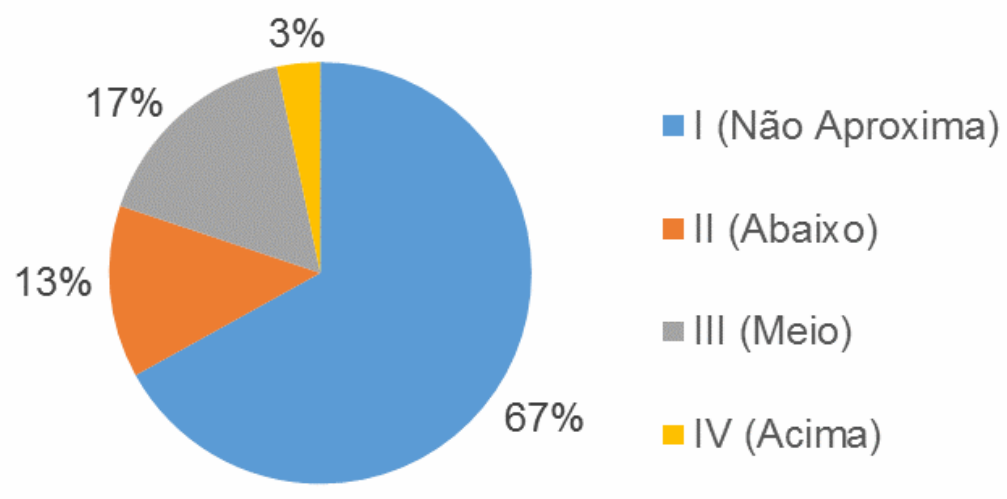

FIGURA 7. Característica da fiação no bairro em estudo.

As espécies que apresentam maiores problemas foram Alfeneiro e o Oiti. Estes indivíduos arbóreos exibiram um estágio de desenvolvimento de adulto a velho. Como estas especeis não apresentam um porte de altura elevada, apesar da idade, pode-se concluir que estas se encontravam em locais inadequados.

Na Figura 8 é apresentada a distribuição da idade dos indivíduos levantados neste estudo. No bairro de Ramos, $42 \%$ dos indivíduos arbóreos se enquadram na fase velha. A fase adulta apresentou o mesmo percentual (42\%). A maior presença de espécies arbóreas na fase adulta e velha não é recomendável. De acordo com Almeida \& Rondo, (2010), quando existe predominância de indivíduos adultos a arborização urbana pode fica comprometida. Uma diminuição da disponibilidade de mudas, por exemplo, pode prejudicar a reposição de indivíduos mortos.

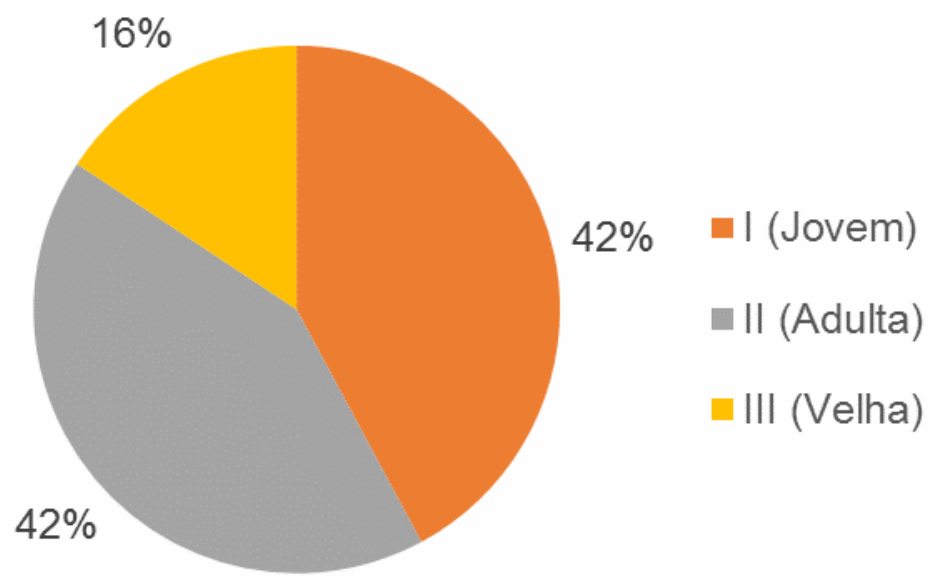

FIGURA 8. Idade dos indivíduos encontrados no Bairro de Ramos.

Da totalidade de indivíduos arbóreos levantados, $47 \%$ se enquadraram na classe de diâmetro de copa $<4 \mathrm{~m}$ e $35 \%$ na classe de 4 a $7 \mathrm{~m}$ (Figura 9). É desejável que na arborização urbana, os indivíduos tenham uma copa densa para favorecer o sombreamento, e subsequente o conforto térmico dos habitantes. 


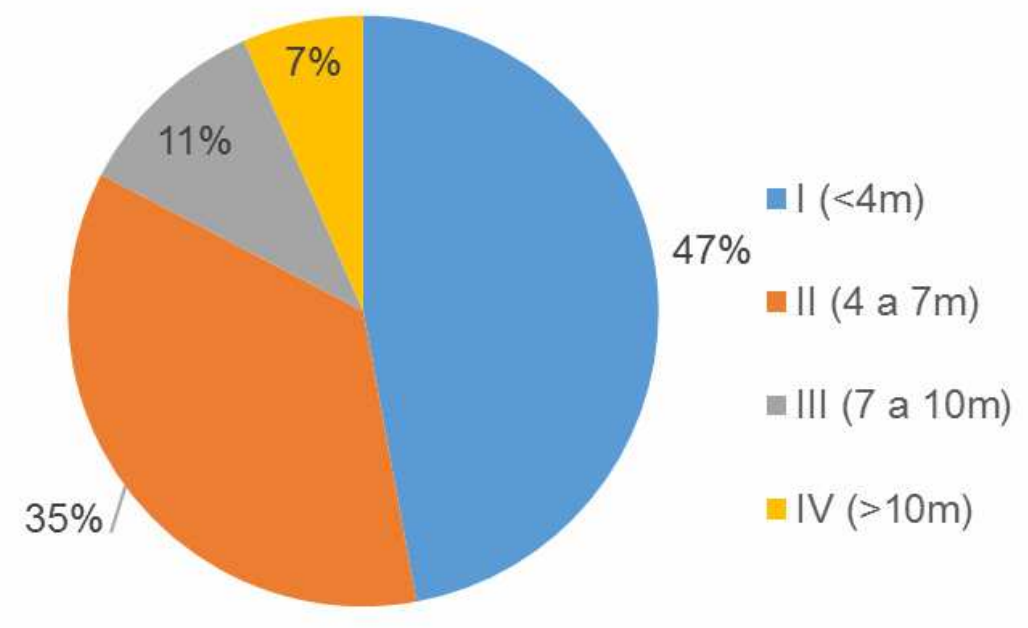

FIGURA 9. Distribuição do diâmetro de copa dos indivíduos levantados.

\section{CONCLUSÃO}

O Bairro de Ramos possui uma insatisfatória intensidade de arborização; além de possuir uma inadequada diversidade de espécies.A maioria das espécies catalogadas nas vias públicas são exóticas, portanto é necessário o incentivo da valorização da flora regional. Durante a realização do inventário percebeu-se que as árvores estão distribuídas de forma inadequada, tornando-se necessário um melhor planejamento de arborização urbana para esta região.

Recomenda-se a definição como área de preservação para os terrenos situados as margens dos recursos hídricos. Além de preservar encostas não construídas com o objetivo de melhorar a recarga hídrica dos cursos d'agua e evitar possíveis deslizamentos de terra e assoreamento dos mesmos. Torna-se necessário a escolha adequada da espécie para arborização urbana de acordo com a declividade, hidrografia e tipo de vegetação. E que esta arborização favoreça a diversidade de espécies e o conforto visual.

\section{AGRADECIMENTOS}

A Sociedade de Investigações Florestais (SIF), Departamento de Engenharia Florestal da Universidade Federal de Viçosa, a Universidade Federal de Viçosa (UFV), a CAPES, ao Laboratório de Painéis e Energia da Madeira (LAPEM), a Fundação de Amparo à Pesquisa de Minas Gerais (FAPEMIG) e a Embrapa Florestas.

\section{REFERÊNCIAS}

BARROS, E.F.S.; GUILHERME, F.A.G.; CARVALHO, R.S. Arborização urbana em quadras de diferentes padrões construtivos na cidade de Jataí. Revista Árvore, v.34, n.2, p.287-295, 2010. Disponível em: <http://dx.doi.org/10.1590/S010067622010000200011 >. doi: 10.1590/S0100-67622010000200011. 
BOBROWSKI, R; BIONDI, D. Distribuição e dinâmica da área de copa na arborização de ruas de Curitiba, Paraná, Brasil, no período de 1984-2010. Revista Árvore, v.36, n.4, p.625-635, 2012. Disponível em: <http://dx.doi.org/10.1590/S010067622012000400005>. doi: 10.1590/S0100-67622012000400005.

BUCKERIDGE, M. Árvores urbanas em São Paulo: planejamento, economia e água. Estudos Avançados, v.29, n.84, p.85-101, 2015. Disponível em: <http://dx.doi.org/10.1590/S0103-40142015000200006>. doi: 10.1590/S010340142015000200006.

GONÇALVES, W.; PAIVA, H.N., Árvores para o ambiente urbano. Viçosa, Aprenda Fácil, 2004. 243 p. (Coleção Jardinagem e Paisagismo. Série Arborização Urbana, 3).

INSTITUTO BRASILEIRO DE GEOGRAFIA E ESTATÍSTICA (IBGE). Censo demográfico 2010. Rio de Janeiro: IBGE, 2011. Acesso em: out. 2016.

KRAMER, J.A.; KRUPEK, R.A. Caracterização florística e ecológica da arborização de praças públicas do município de Guarapuava, PR. Revista Árvore, v.36, n.4, p.647-658, 2012. Disponível em: <http://dx.doi.org/10.1590/S010067622012000400007>. doi: 10.1590/S0100-67622012000400007.

LORENZI, H. Árvores Brasileiras: Manual de Identificação e cultivos de plantas arbóreas do Brasil. 2ª . Nova Odessa, Editora São Paulo, 2002. 368p.

MALTA, J.A.O.; SOUZA, H.T.R.; SOUZA, R.M. Fitogeografia e regeneração natural em florestas urbanas de São Cristóvão/SE-Brasil. Investigaciones geográficas, v.4, n.77, p.48-62, 2012. Disponível em: <http://www.scielo.org.mx/pdf/igeo/n77/n77a5.pdf>. S018846112012000100005.

MARTINI, A.; BIONDI, D. Microclima e Conforto Térmico de um Fragmento de Floresta Urbana em Curitiba, PR. Floresta e Ambiente, v. 22, n.2, p.182-193, 2015. Disponível em: < http://dx.doi.org/10.1590/2179-8087.082114>. doi: 10.1590/21798087.082114.

MELO, E.F.R.Q.; PIACENTINI, C.A.M. Diversidade da Arborização Urbana no Município de Colorado (RS). Ambiência, v.7, n.2, p.339-352, 2011.

MILANO, M.; DALCIN, E. Arborização de vias públicas. Rio de Janeiro. Light, 226 p. 2000.

SALVI, L.T.; HARDT, L.P.A.; ROVEDDER, R.E.; FONTANA, C.S. Arborização ao longo de ruas - túneis verdes - em Porto Alegre, RS, Brasil: avaliação quantitativa e qualitativa. Revista Árvore, v.35, n.2, p.233-243, 2011. Disponível em: <http://dx.doi.org/10.1590/S0100-67622011000200008>. doi: 10.1590/S010067622011000200008. 
SANTOS, C.Z.A.; FERREIRA, R.A.; SANTOS, L.R.; SANTOS, L.I.; GOMES, S.H.; GRAÇA, D.A.S. Análise qualitativa da arborização urbana de 25 vias públicas da cidade de Aracaju - SE. Ciência Florestal, v.25, n.3, p.751-763, 2015. Disponível em: <http://dx.doi.org/10.5902/1980509819678>. doi: 10.5902/1980509819678.

SILVA FILHO, D.F.S.; PIZETTA, P.U.C.; ALMEIDA, J.B.S.A.; PIVETTA, K.F.L.; FERRAUDO, S. Banco de dados relacional para cadastro, avaliação e manejo da arborização em vias públicas. Revista Arvore, v.26, n.5, p.629-642, 2002. Disponível em: <http://dx.doi.org/10.1590/S0100-67622002000500014>. doi: $10.1590 / \mathrm{S} 0100-67622002000500014$. 